удк 930

DOI https://doi.org/10.24866/1997-2857/2021-3/37-45

\title{
А.А. Тесля* \\ АВТОНОМИЯ, ИСТОРИОГРАФИЧЕСКИЕ АЛЬТЕРНАТИВЫ И ИДЕОЛОГИЧЕСКАЯ БОРЬБА В ИСТОРИЧЕСКОЙ НАУКЕ «ЗРЕЛОГО СТАЛИНИЗМА»
}

\author{
Рец.: Киселев М.А. «Регулярное» государства Петра I \\ в сталинской России. Судьбы историков права \\ в контексте научных и идеологических баталий \\ советского времени. СПб.: Нестор-История, 2020
}

\begin{abstract}
В статье рецензируется книга екатеринбургского историка Михаила Киселева, посвященная формированию и развитию исторических и историко-правовых взглядов советского историка Б.И. Сыромятникова в контексте устройства исторического сообщества и научной коммуникации внутри него в эпоху «зрелого сталинизма».

Ключевые слова: историография, история права, советская историческая наука, петровские реформы
\end{abstract}

Autonomy, historiographical alternatives and ideological battles in the discipline of history under mature Stalinism. A review of "The "regular" state of Peter I in Stalinist Russia. The fate of legal historians in the context of scholarly and ideological debates of the Soviet era» (2020) by Mikhail Kiselev. ANDREY A. TESLYA (Immanuel Kant Baltic Federal University)

The article reviews a book by Mikhail Kiselev, a historian from Yekaterinburg, dedicated to a Soviet historian Boris Syromyatnikov, his views on Russian history and the history of law in the context of the structure of historical community and scholarly communication within it in the era of mature Stalinism.

Keywords: historiography, history of law, Soviet discipline of history, reforms of Peter the Great

Имя Бориса Ивановича Сыромятникова (18741947) не очень хорошо известно за пределами исторического сообщества, да и в его границах не относится к числу первенствующих. Работы о нем стали появляться, по большому счету, лишь с 2000-х гг. (см.: [3; 5]). Монографию М.А. Киселева можно в этом контексте представить именно как ответ сразу на обе части вопроса: и почему имя Сыромятникова и если не идеи, которые он разделял, то во всяком случае связка их с его именем, оказались полузабыты; и почему это (полу) забвение, само по себе процесс более чем естественный в любой сфере человеческой жизни и деятельности, представляет интерес.

* ТЕСЛЯ Андрей Александрович, кандидат философских наук, старший научный сотрудник, научный руководитель Центра исследований русской мысли Института гуманитарных наук Балтийского федерального университета им. И. Канта.

E-mail: mestr81@gmail.com

(C) Тесля А.А., 2021 
Обращение к истории русской исторической науки сталинского периода прошло за последнюю треть века несколько этапов. Впрочем, первый из них отчасти уже намечался в работах «третьей эмиграции», как научных, так и публицистических и мемуарных - обличение злодеев и память о жертвах, а в каких-то случаях - восхваление если не героев в привычном смысле слова, то тех, кто находил в себе силы не участвовать, не обличать, и если и лицемерить, то лишь в таких рамках, где между лицемерием и соблюдением принятых обычаев грань провести затруднительно.

Предсказуемым образом, основной акцент здесь делался (и делается в той мере, в которой продолжают появляться работы, продолжающие сложившуюся в рамках этого этапа традицию) на обличении злодеев. Конкретизация зла, его персонификация (при этом либо вынесение его прежде всего вовне, понимание в качестве его источника и причины - политической и идеологической власти, а не научного сообщества, либо указание конкретных персоналий из числа самого научного сообщества ${ }^{1}$ ) позволяла вместе с тем локализовать проблему - обратить ее в проблему морального/политического падения конкретных людей, когда само сообщество оставалось незапятнанным.

Конкретно-историческое изучение уже довольно скоро продемонстрировало всю неприемлемость концепции «тоталитаризма»: историки оказывались раз за разом, при рассмотрении конкретных ситуаций, отнюдь не только объектами воздействия, демонстрируя более или менее сложно устроенную субъектность. Таким образом, уже довольно скоро внимание обратилось с уровня взаимодействия «власть историки» на более сложные сюжеты, исходящие в той или иной степени из признания как неоднородности самой «власти», так и разнородности «историков», начиная с очевидного что для разных областей исторического знания

\footnotetext{
${ }^{1}$ В свою очередь это порождало сложную проблему соотнесения пагубной роли лица с его научными заслугами: предсказуемо, что в отношении тех, за кем последние трудно было отрицать, возникало стремление либо уменьшить степень вины, либо, напротив, отрицать научный вклад соответствующего лица, значение его трудов с точки зрения научного знания (наиболее показательным примером последнего рода служит М.Н. Покровский, когда кампания, открытая против его «школы» в 1934 г., воспринимается как род законного воздания).
}

положение вещей сильно разнится в пределах одного и того же периода времени ${ }^{2}$.

Более того, довольно скоро стало понятно, что отчетливо отграничить научные споры от использования - добросовестного или конъюнктурного - идеологических обвинений применительно к истории русской исторической науки 1920-х - 1950-х гг. затруднительно, даже если придерживаться жесткого противопоставления науки и идеологии в концептуальном плане (идя, например, в понимании «науки» по позитивистской/неокантианской линии). Сам исторический материал, независимо от принятия тезиса о возможности отчетливо отделять «научное» от «не-научного» в плане знания, не позволяет осуществлять такого рода принципиальное разграничение на уровне как описания действий сторон, так и устройства используемых ими аргументов. На уровне исторического описания обнаруживается не только переплетенность «науки» и «идеологии», но и невозможность в большинстве случаев описывать противостояние как столкновение защитников «науки» с их оппонентами, стремящимися подчинить науку идеологии. Эта ситуация конкретного исследования ведет к невозможности продолжать первую из упомянутых нами моделей описания прошлого отечественной исторической науки или, по крайней мере, невозможности отождествлять «злодеев» с идеологами, а жертв - с борцами за науку.

Другим вопросом, возникшим достаточно поздно и рассматриваемым на материале одного конкретного сюжета в работе М.А. Киселева, оказалась парадоксальным образом сохраняющаяся и производящаяся альтернативность научных концепций и подходов в рамках «зрелого сталинизма». Разумеется, преувеличивать последнюю не стоит: курс на упорядочивание, а затем и монополизацию в каждой конкретной области определился довольно рано - начиная с ликвидации разнообразия писательских организаций и утверждения одного Союза советских писателей в 1934 г. и вплоть до аналогичных процессов в музыке, журналистике и академической науке. Иерархически выстроенное целое, на первый взгляд, должно было маргинализировать подходы и теории, противоречащие утверждаемым институциям, ответственным за соответствующее направление. Во многом так

${ }^{2}$ Понятно, что для 1930-х гг. более чем различны обстоятельства, например, историков русского революционного движения и медиевистов. 
и происходило, но далеко не столь полно, как можно было бы предполагать.

Концептуальный ответ на вопрос о том, как оказывалась возможной альтернативность и более или менее успешное формирование групп, а в потенциале и школ, противостоящих авторитету и власти подходов, утверждаемых ответственными за соответствующее направление научными институциями, достаточно прост. Суть его сводится к тому, что в случае исторического знания сообщество «сугубо-историков» не оказывалось его монополистом. Помимо «собственно истории», в силу историзма, присущего модерному знанию, другие области, прежде всего - гуманитарные и социальные науки, обладали собственными, более или менее автономизированными версиями исторического и при этом были способны оказывать определенное влияние на «большую историю». Так, например, история государства и права, история политических учений, относясь к области «юридических наук» (и, в рамках советской Академии, к другому отделению, чем историки), находились вне возможностей по крайней мере прямого воздействия со стороны, например, руководства Института истории $\mathrm{AH} \mathrm{CCCP}^{3}$.

Биография Сыромятникова одновременно и своеобразна, и типична для его времени. Он принадлежит к поколению ученых, которые успели так или иначе обозначить себя, заслужить некоторую научную репутацию до революции. Выпускник юридического факультета Московского университета, оставленный при университете для подготовки к профессорскому званию, при этом весьма активный в общественной и просветительской деятельности, он в 1911 г. покидает университет вместе с рядом других профессоров и приват-доцентов в знак протеста против увольнения решением министра народного просвещения ректора А.А. Манилова и профессоров М.А. Мензбира и П.А. Минакова. С этого момента он становится одним из ключевых деятелей Общества народных университетов: с 1912 г. работает товарищем председателя, а с 1914 г. - председателем общества, с 1910 г. преподает в Народном

3 Другим примером, который вспоминает сам автор в заключительной главе, будет история тартуско-московской семиотической школы, существенным образом повлиявшей на исторические исследования в целом ряде областей, прежде всего - в изучении отечественной истории XVIII-XIX вв. университете им. Шанявского. Научная продуктивность его в эти годы, предсказуемо, довольно ограничена: в основном он подготавливает научно-популярные работы. Февральская революция приводит к возвращению в Московский университет уволенных и ушедших вслед за ними, в том числе и Сыромятникова, который одновременно развивает публицистическую активность на волне революционных событий, принадлежа к левым кадетам (в газетах он более или менее активно сотрудничает еще с начала века). Как и большая часть коллег, большевиков он не примет. Почти непосредственно перед революцией происходит и большая перемена в его личной жизни - он уходит от своей первой и начинает жить с М.П. Кашириной.

В первой половине 1920-х гг. - и в этом вновь скорее типичная черта времени и среды, к которой он принадлежит - Сыромятников одновременно или последовательно работает в разных местах, пытаясь закрепиться: какое-то время деканствует на общественно-философским отделении Университета им. Шанявского, много сил и энергии вкладывает в организацию работы Ивано-Вознесенского политехнического института, в том числе привлекая ведущих московских гуманитариев, читает лекции на рабфаке, преподает в Межевом институте. В 1928 г. перебирается в Казань, где преподает два года, и затем возвращается в Москву (очень вовремя, как показывает современный биограф, поскольку буквально в следующие за его отьездом месяцы начнет набирать силу кампания против старых специалистов и имя Сыромятникова будет неоднократно упоминаться в самом тревожном контексте). По возращении в Москву устраивается заведующим библиотекой Центрального научного-исследовательского текстильного института (НИТИ), откуда выходит на пенсию.

К этому времени его биография кажется в целом завершенной и в научном плане достаточно бледной. Наибольшее значение имеет так и оставшаяся недописанной докторская диссертация, в обстоятельном введении к которой анализируются теории русского исторического процесса. В свое время обратили на себя внимание его работы по истории декабризма, прежде всего обстоятельное исследование политико-правовых взглядов Пестеля. В мемориальном сборнике о В.О. Ключевском, приглашение к участию в котором само по себе было весомым знаком принятия научным сообществом, 
Сыромятников поместил статью, сопоставлявшую взгляды В.О. Ключевского и Б.Н. Чичерина. В 1920-е гг. выступил с нашумевшей среди профессионалов статьей о восстании декабристов как о «последнем дворцовом перевороте». В 1930-е гг. он публикует статьи, некоторые из которых достигают солидного объема, в «Энциклопедическом словаре братьев Гранат», но эти публикации проходят почти незаметно (примечательно, что даже в библиографию Сыромятникова 2012 г. они по большей части окажутся не включены).

И здесь его биография делает решительный поворот - постановления 1934 и 1936 гг. о преподавании истории обозначают существенную перемену не только в исторических дисциплинах, но и в связанных с ними. Уже на исходе 1935 г. Сыромятников обращается в Аттестационную комиссию при Коммунистической академии с прошением о присвоении ему на основании опубликованных работ научного звания (прошение будет удовлетворено только в 1938 г. - он станет доктором юридическим наук). 25 октября 1936 г. Институт советского строительства и права преобразовывается в Институт государственного права СССР, чтобы затем стать уже просто Институтом права. Обозначается необходимость в историко-правовых исследованиях, как и в трудах по догме права - курс, который еще отчетливее 4 обозначится после назначения нового директора - А.Я. Вышинского.

Поворот 1934-1938 гг. изменит и судьбу Сыромятникова, и судьбу его заклятого врага на ближайшие годы - С.В. Юшкова, также историка-юриста еще старой школы. Юшков к 1938 г. сможет вырваться из Свердловска и станет ведущим специалистом по истории права в рамках Московского юридического института. Сыромятников получит степень доктора и быстро займет довольно заметную позицию в Институте права, примет в конце 1930-х - начале 1940-х гг. участие в дискуссиях с Б.Д. Грековым и с С.В. Юшковым и станет руководителем историко-правового направления работ института. В этом карьерном взлете недавнего пенсионера - сочетание целого ряда обстоятельств. Прежде всего, речь идет о проявившейся потребности в специалистах по истории права - дисциплины, которая фактически от-

${ }^{4}$ После кровавой мешанины 1937 г., когда погибнут и прежний директор института, Е.Б. Пашуканис, и его заместитель Н.И. Челяпов. сутствовала на протяжении предшествующих двух десятилетий, и, соответственно, все подготовленные специалисты в этой области были не просто представителями дореволюционной науки, но успели оформиться как профессионалы именно в период до 1917-1918 гг. Вместе с тем, ряд специалистов близкого профиля уже обрели позиции в рамках формирования собственно исторических институций после поворота 1934 г., так что круг лиц, из которого можно было выбирать, еще более сужался. Благоприятствовало и то обстоятельство, что Сыромятников был специалистом широкого профиля: если относительно глубины его исследований есть разногласия, то во всяком случае он был компетентным, квалифицированным историком права и политических учений. И, наконец, третий фактор - расположение и поддержка со стороны А.Я. Вышинского, видимо, сохранявшиеся и после того, как тот перестал быть руководителем Института права [5, с. 105-156].

Первые годы работы в институте для Сыромятникова ознаменуются прежде всего его критикой исторической концепции Б.Д. Грекова. Но это столкновение окажется не только не особенно перспективным, по крайней мере с точки зрения дирекции института, но и не очень выигрышным при внимательном рассмотрении позиции Сыромятникова. Последний не был знатоком древнерусской истории и по большому счету атаковал Грекова и его сторонников, с одной стороны, с опорой на тот вариант марксистской интерпретации исторического процесса, что утвердился после выхода «Краткого курса...» (1938), а с другой - на дореволюционную литературу по теме. На первом ходе это могло показаться довольно удачной комбинацией, по крайней мере Сыромятников выступал как блюститель марксистской ортодоксии (что он попытается повторить и в «"Регулярном" государстве...»), тогда как, по выражению А.А. Зимина, до-феодальная Русь Грекова была «шалостью», на которую, правда, тот «получил высочайшее (молчаливое) соизволение ... в благодарность за преданность» [4, с. 42]. К тому же он выступал здесь в согласии с критикой Грекова со стороны его собственного заместителя, Шестакова. Однако полемика с точки зрения рабовладельческой концепции истории Древней Руси все хуже идеологически звучала на рубеже 1930-х - 1940-х гг., начиная восприниматься как «принижающая» русское прошлое. Так что поворот Сыромятникова к новой теме - Петру I, 
его реформам и теории «регулярного» или «полицейского» государства - представляется одновременно и выходом из конфликта, который в 1940 г. перестал сулить победу, и обращением к проблематике, созвучной новым вызовам, в том числе быстрому переосмыслению фигуры Петра I (примером динамики здесь служит эволюция его образа в произведениях А.Н. Толстого 1920-х - 1940-х гг. [2, с. 112-126]).

Новая тема оказывалась выигрышной еще и потому, что позволяла избавиться от слабости в области фактического материала - не только сам Сыромятников был хорошо знаком с политической и правовой литературой той эпохи и посвященными ей работами, но именно в это время он знакомится с подготовленным ленинградским историком-самоучкой Н.А. Воскресенским уникальным собранием «Законодательных актов Петра Великого», которые решает публиковать Институт права 5 . Таким образом, под предлагаемую им концепцию он имеет возможность сразу же подложить принципиально новую эмпирическую базу, а обе работы оказываются плодами деятельности института и возглавляемого Сыромятниковым сектора.

«"Регулярное” государство Петра I и его идеология» - книга одновременно и быстро написанная, и итоговая. «Быстро» в данном случае характеристика не столько времени, которое заняло ее написание, сколько внутреннего устройства: в значительной части она собрана из материалов Сыромятникова, относящихся еще к 1900-1910 гг., а там, где этих материалов не было, остаются либо пробелы, либо произвольные конструкции, призванные их закрыть (самым ярким примером этого рода станет анализ взглядов на Петра I и петровские реформы во второй четверти XIX в., в котором разнообразие мнений сведено к противостоянию западников и славянофилов, а все значимые участники дискуссии «подверстаны» к одной из этих позиций $\left.{ }^{6}\right)$. Еще более характерна значительная

\footnotetext{
${ }^{5}$ Публикация затянется: первый том, так и оставшийся единственным изданным, выйдет только в 1945 г., так что в результате образуется исторический курьез - рецензия Сыромятникова на «Законодательные акты...» Воскресенского выйдет за пять лет до издания самой книги [8].

${ }^{6}$ Так, характеризуя воззрения 1830-х - 1840-х гг. на петровские реформы, Сыромятников сводит все разнообразие позиций до Чаадаева, западников и славянофилов, при этом не дифференцируя от последних, например, М.А. Погодина. Подобного рода
}

часть историографического обзора, посвященная историкам последней трети XIX - начала XX в., - от В.О. Ключевского до С.Ф. Платонова и П.Н. Милюкова, а во многом - и пониманию эпохи Петра I в трудах С.M. Соловьева. Фактически Сыромятников ограничивается рассмотрением общих суждений и характеристик, вводных и заключительных параграфов соответствующих курсов, оставляя за пределами анализа конкретное изложение материала, распределение акцентов, выделение значимых реформ и протекающих в связи с ними или синхронно процессов. Эксплицитное заключение рассматриваемых им авторов, учеником одного из которых он сам определял себя в статье, помещенной в «Энциклопедическом словаре братьев Гранат» уже в конце 1920-х гг, приравнивается к пониманию ими петровских преобразований и их места в русской истории. То обстоятельство, что в других случаях автор действует иначе, прикладывая намного более существенные усилия к реконструкции аргументов рассматриваемых исследователей, демонстрирует отмеченную спешность работы, неравновесность ее частей.

Как уже отмечалось, большая часть работы Сыромятникова - критический историографический обзор, особенно в той части, где он переходит к современникам. Но, выделяя ядро его концепции, мы отметим три момента:

- во-первых, стремление акцентировать и разграничить сословно-представительную монархию и абсолютизм (с остающимся не до конца проясненным статусом «просвещенности»);

- во-вторых, стремление определить социальную базу каждой из названных политических форм - отнюдь не только в рамках марксистской ортодоксии, но прежде всего продолжая логику научного движения конца XIX - начала XX вв. и свои собственные теоретические интересы;

решение можно было бы счесть просто небрежностью и следованием за расхожими представлениями, если бы не высокая историографическая подготовка автора. При помощи этого хода он фактически обходит вопрос о прославлении реформ Петра I и помещении его в центр своей концепции русской истории Погодиным, как и вопрос об официальном и официозном культе Петра I, столь характерном для николаевской эпохи. Тем самым он выстраивает схему, в которой позитивное отношение к Петру I и его реформаторской деятельности оказывается тождественным прогрессивным взглядам, а отрицательное, соответственно, - консервативным. 
- в-третьих, попытку, оставшуюся в опубликованном тексте скорее фрагментами замысла, понять конкретно-исторически «идеологию» не как внешнюю форму, а через взаимодействие базиса и надстройки, с неполной автономией последней, относя это и к автономии государства, и к автономии идеологии по отношению к наличному государству, что в свою очередь означало и способность идеологии выступать в качестве автономного преобразовательного фактора.

В конспекте введения и первой главы монографии, опубликованном в 1940 г. тиражом в 50 экз., Сыромятников писал, что инструментами петровской реформы стали: (1) политическая теория и (2) «практика европейских государств» [5, с. 162], идея «полицейского государства». Используя актуально-политический язык момента, Сыромятников писал, что Петр верил «в чудесную силу “просвещенного" насилия» и «стремился форсировать исторический процесс, полагая не только догнать, но и перегнать своих западных “учителей”», однако «чуда не случилось» [5, с. 163] (ср.: [5, c. 179]). Вопрос, который возникает по поводу этих слов: насколько целенаправленными, сознательными были аллюзии на современность, тем более, как вспоминал Вяч.Вс. Иванов уже о второй половине 1930-х гг., для Сыромятникова было характерно «воинственное отрицание большевиков» $[5$, с. 31$]$.

Суммируя свою интерпретацию концепции Сыромятникова, Киселев пишет: «...По Б.И. Сыромятникову, бюрократическое государство при определенных исторических условиях может попытаться ускорить развитие страны с целью ликвидации отсталости, опираясь при этом на идеи и практики, заимствованные из более развитых стран. Правда, результативность такой попытки в немалой степени будет ограничена текущим уровнем развития. В то же время С.А. Покровский ${ }^{7}$ приходил к выводу, что по-

\footnotetext{
${ }^{7}$ Серафим Александрович Покровский, коллега и ученик Сыромятникова, специалист по истории русских политико-правовых учений XVIII-XIX вв. Наибольшую своеобразную известность приобрел в 1950-е гг., когда его роль как осведомителя стала известной и официально признанной. Отметим, что вопреки расхожей легенде, после разоблачения его карьера хоть и пострадала, однако он продолжал участвовать в интеллектуальной жизни - в частности, уже в конце 1960-х гг. принял участие в известной дискуссии о славянофилах на страницах «Вопросов литературы». О последних полутора десятилетиях его жизни и деятельности см.: [5, с. 363-366].
}

литика догоняющей модернизации может приводить к противоречивым результатам и не только способствовать модернизации, но и консервировать немодерные отношения и в итоге тормозить модернизационное развитие. Это он иллюстрировал тем, что петровская политика “догнать Европу" скорее способствовала не развитию буржуазных отношений, а усилению крепостничества. Ведь получалось, что для проведения модернизационной политики приходилось обращаться к тем средствам, которые могло предоставить немодерное общество, т.е. к крепостному праву. Заметим, что в 1968 г. Л.В. Черепнин на советско-итальянской конференции историков рассуждал примерно в таком же духе, беря за отправную точку как раз концепцию Сыромятникова» [5, с. 171].

Книга Сыромятникова встретит сначала критическую, а затем в пределах 1944 г. все более неприемлющую реакцию, в том числе оказавшись одним из объектов критики на известном собрании историков 1944 г. [2; 10]. Основной линией критики Сыромятникова будет сближение его концепции с воззрениями Покровского - в частности, его будут обвинять в возрождении объяснения петровских реформ через «торговый капитализм» ${ }^{8}$. Однако, как показывает Киселев, критика Сыромятникова отнюдь не была сокрушительна в смысле исключения его и его научных трудов из рамок советской науки: он сохранил свои основные позиции в Институте права и оставался достаточно активен вплоть до своей кончины в 1947 г. Таким обра-

${ }^{8}$ Киселев справедливо напоминает, что само понятие «торгового капитала» применительно к русской истории связано с Туган-Барановским и его работой «Русская фабрика» (1898). При этом, однако, достаточно сомнительно стремление Киселева старательно разграничить понятия «торгового капитала» и «торгового капитализма», отмечая, что в отличие от Покровского Сыромятников вторым никогда не пользовался. На наш взгляд, в этом - отголосок уже поздней, 1930-х гг. концептуализации и переосмысления марксистской политэкономии и исторического материализма и утверждения «капитализма» как одного (в смысле единичности, уникальности) этапа развития человеческого общества. Так, в большой концептуальной статье 1906 г. Сыромятников интерпретирует циклические концепции, в частности остроактуальную на тот момент концепцию Эд. Мейера, как утверждение единства исторического процесса в том смысле, что «все народы развивались аналогичныл путем, проходя одинаковые этапы, повинуясь одним и тем же законам развития» [3, с. 97]. 
зом, невозможно лишь критикой этого времени объяснить столь прочный отход наследия Сыромятникова на периферию последующего развития исторической науки. Впрочем, здесь стоит отметить и границы социологизма. Если вопрос о том, как оказалось возможным более или менее ощутимое противостояние господствующему подходу, разрешается успешно, то социологизирующая трактовка ответа на вопрос о том, почему не сложилась школа Сыромятникова, требует существенных оговорок уже не вполне или не только социологического плана.

Показательно, что именно то, в чем будут упрекать Сыромятникова в спорах 1944 г., как раз изначально и составляет по крайней мере заявляемое им самим ядро работы: попытка определить классовый характер петровского государства, характеристика которого в этом отношении фактически объявляется отсутствующей у предшествующих и современных исследователей (см.: [7, с. 299-300]). Это, во-первых, стремление и склонность самого Сыромятникова именно к концептуальному анализу - то, что историк с другими представлениями об идеале научности, М.М. Богословский, оценил как «пустозвонство» ${ }^{9}$. Во-вторых, стремление опереться на официальные исторические представления/конструкции и атаковать оппонентов с точки зрения отступления от них. В данном случае первая черта - относительная сила концептуального анализа и склонность к нему - ведет к попытке построения теоретически непротиворечивой, последовательной исторической схемы.

Прежде всего отметим, что Сыромятников, собственно, не предложил - вопреки амбициозным заявлениям - собственной развернутой трактовки петровских реформ. И проблема даже не в том, что “"Регулярное" государство...» по большей части так и осталось в границах историографического обзора ${ }^{10}$, при этом во многом

\footnotetext{
9 Запись в дневнике от 8.II.1916 г. Чуть ранее, в записи от 21.I.1916 г. М.М. Богословский характеризует Сыромятникова как «левого пустозвона» [1, c. 143, 136]. В этом, на наш взгляд, не только различие политических позиций. Значимо здесь и различие дисциплинарных пространств - историко-юридического исследования и «собственно исторического», делающего упор к этому времени прежде всего на архивных изысканиях и введении в научный оборот нового материала, а не концептуальном осмыслении уже имеющегося.

10 Хотя в данном случае и осмелимся предположить, что это - вряд ли случайность. Ведь и дис-
}

полемически-заостренного, временами почти «газетного» в стилистическом плане. Ключевое затруднение в том, что сама концепция Сыромятникова оказывается данной в ряде положений, достаточно слабо подкрепленных материалом, - положений, даваемых в полемике, отталкивании от других.

«Школа» предполагает наличие того, кого можно представить как «классика», а для этого необходимо наличие того, что можно осмыслить как «классические тексты», «фундаментальные исследования». В этом плане история не случившейся «школы Сыромятникова» важна сопоставлением не только с Грековым, но и с Юшковым, оставляющим, пусть и вызывающие обостренную критику со стороны Сыромятникова, развернутые учебные курсы и учебные издания по истории русского государства и права. Противопоставить этому Сыромятников может - и, кстати, в «"Регулярном" государстве...» прямо и пытается - свой собственный литографированный курс, еще 1909-1910 гг. (см.: [7, с. 320, 321]).

В случае с несостоявшейся «школой Сыромятникова» мы, как представляется, упираемся в итоге не только в историю «обстоятельств», но и собственно в качество - уровень, масштаб, обстоятельность проделанной работы. Фактически Сыромятников предлагает ряд наблюдений и плодотворных замечаний, предлагает то, что потенциально может стать фундированной концепцией, но таковой в его изложении еще не является.

Его клиентелу представляют по большому счету лишь двое - с одной стороны, явный маргинал Воскресенский, с другой - «красный историк» и осведомитель Покровский. При этом для второго концепция Сыромятникова вряд ли на первом месте, он примыкает к нему скорее как к авторитетному в рамках Института права лицу, занимается близкими сюжетами, но

сертация Сыромятникова, так и оставшаяся незавершенной, ограничилась в законченной части именно историографией. Видимо, Сыромятникову было сложно переходить к конкретно-историческому изучению материала. Показательно, что работ такого плана в его библиографии весьма немного, а те, что есть, посвящены вновь исключительно истории идей. Задуманная им работа о Петре I предполагала принципиальный выход за пределы привычной для него рамки - совмещения доктринального уровня, истории идей и истории законодательства, с практикой, с тем, как это законодательство воплощалось и чем оказывались эти нормы в своей реализации. 
концептуальная близость здесь носит довольно ограниченный характер. Воскресенский же не может сам стать «силой», его включенность в научное сообщество более чем ограничена - он, как легко судить по фрагментам писем, опубликованным его биографом Д.О. Серовым, не отграничивает себя от предмета своего изучения, многолетняя изолированная работа над законодательством Петра I приводит его к неспособности слышать другие точки зрения, учитывать критику его исследовательских приемов [6; 5 , c. 249-269].

Словом, Сыромятников стар, не обладает достаточным количеством учеников и не успевает обрести их, плохо завоевывает союзников и, благодаря в том числе плохому характеру, легко находит все новых врагов. При этом он не создает работы, которую можно было бы охарактеризовать как фундаментальную. Именно поэтому, как показывает Киселев, обращение последующих историков происходит лишь к отдельным его тезисам - непосредственно или из вторых рук, не возникает репутационного веса, который побуждал бы перечитывать научное наследие Сыромятникова и работать с ним как с целым.

Завершая небольшое эссе, посвященное замечательной работе М.А. Киселева, вновь обратимся к сюжету, с которого начали: о сложности описания позиции историка, невозможности свести ее к простой схеме, например, противостояния или подчинения идеологическому диктату. Так, остающийся по крайней мере в середине 1930-х гг. воинствующим противником «большевиков», Сыромятников выстраивает свою научную позицию в спорах конца 1930-х - начала 1940-х гг. не просто как марксистскую, а как ультра-ортодоксальную, с прямолинейной опорой на «Краткий курс...» и проецированием его постулатов на исторический материал. Это можно было бы описать как двойственность, ограничившись моральным суждением, но ситуация по меньшей мере осложняется тем, что именно в этой, поздней позиции, где трудно както отграничить науку от идеологии, Сыромятников, анализируя петровские реформы, трактует их как ставшие возможными в силу автономии государства, как попытку сверху трансформировать общество и само государство в соответствии с желанным, воображаемым идеалом, в итоге обреченную даже не только и не столько на «неудачу», сколько на получение результата, принципиально отличного от задуманного.

\section{СПИСОК ЛИТЕРАТУРЫ}

1. Богословский М.М. Дневники (19131919): Из собрания Государственного Исторического музея. М.: Время, 2011.

2. Дубровский А.М. Власть и историческая мысль в СССР (1930-е - 1950-е гг.). М.: Политическая энциклопедия, 2017.

3. Дурновцев В.И., Тихонов В.В. Жизнь и труды историка Б.И. Сыромятникова. М.: Канон+; РООИ «Реабилитация», 2012.

4. Зимин А.А. Храм науки (Размышления о прожитом) // Судьбы творческого наследия отечественных историков второй половины XX в. М.: Аквариус, 2015. С. 35-383.

5. Киселев М.А. «Регулярное» государства Петра I в сталинской России. Судьбы историков права в контексте научных и идеологических баталий советского времени. СПб.: Нестор-История, 2020.

6. Серов Д.О. Н.А. Воскресенский (18891948) - подвижник науки истории русского права // Воскресенский Н.А. Петр Великий как законодатель: Исследование законодательного процесса в России в эпоху реформ первой четверти XVIII века. М.: Новое литературное обозрение, 2017. С. 5-58.

7. Сыромятников Б.И. «Регулярное» государство Петра I и его идеология // Дурновцев В.И., Тихонов В.В. Жизнь и труды историка Б.И. Сыромятникова. М.: Канон+; РООИ «Реабилитация», 2012. С. 194-410.

8. Сыромятников Б.И. Рец.: Воскресенский Н.А. Законодательные акты Петра Великого. T. I. Акты о высших государственных установлениях. Л., 1940. 926 с. // Советское государство и право. 1940. № 11. С. 121-129.

9. Тихонов В.В. Исторические кампании «позднего сталинизма» и советская историческая наука: середина 1940-х - 1953 г. СПб.: Нестор-История, 2016.

10. Юрганов А.Л. Русское национальное государство: Жизненный мир историков эпохи сталинизма. М.: Изд-во РГГУ, 2011.

\section{REFERENCES}

1. Bogoslovskii, M.M., 2011. Dnevniki (1913-1919): Iz sobraniya Gosudarstvennogo Istoricheskogo muzeya [Diaries of 1913-1919): From the funds of the State Historical Museum]. Moskva: Vremya. (in Russ.)

2. Dubrovskii,A.M., 2017. Vlast'i istoricheskaya mysl'v SSSR (1930-e - 1950-e gg.) [Power and 
historical thought in the USSR, 1930s-1950s]. Moskva: Politicheskaya entsiklopediya. (in Russ.)

3. Durnovtsev, V.I. and Tikhonov, V.V., 2012. Zhizn' i trudy istorika B.I. Syromyatnikova [The life and works of historian Boris Syromyatnikov]. Moskva: Kanon+; ROOI «Reabilitatsiya». (in Russ.)

4. Zimin, A.A., 2015. Khram nauki [Temple of knowledge]. In: Sud'by tvorcheskogo naslediya otechestvennykh istorikov vtoroi poloviny $\mathrm{XX}$ veka. Moskva: Akvarius, 2015, pp. 35-383. (in Russ.)

5. Kiselev, M.A., 2020. «Regulyarnoe» gosudarstvo Petra I v stalinskoi Rossii. Sud'by istorikov prava $\mathrm{v}$ kontekste nauchnykh i ideologicheskikh batalii sovetskogo vremeni [The «regular» state of Peter I in Stalinist Russia. The fate of legal historians in the context of scholarly and ideological debates of the Soviet era]. SanktPeterburg: Nestor-Istoriya. (in Russ.)

6. Serov, D.O., 2017. N.A. Voskresenskii (18891948) - podvizhnik nauki istorii russkogo prava [N.A. Voskresensky (1889-1948), an ascetic of the history of Russian law]. In: Voskresenskii, N.A., 2017. Petr Velikii kak zakonodateli: Issledovanie zakonodatel'nogo protsessa $\mathrm{v}$ Rossii $\mathrm{v}$ epokhu reform pervoi chetverti XVIII veka. Moskva: Novoe literaturnoe obozrenie, pp. 5-58. (in Russ.)

7. Syromyatnikov, B.I., 2012. «Regulyarnoe» gosudarstvo Petra I i ego ideologiya [The «regular» state of Peter I and its ideology]. In: Durnovtsev, V.I. and Tikhonov, V.V., 2012. Zhizn' i trudy istorika B.I. Syromyatnikova. Moskva: Kanon+; ROOI «Reabilitatsiya», pp. 194-410. (in Russ.)

8. Syromyatnikov, B.I., 1940. [Rets.:] Voskresenskii N.A. Zakonodatel'nye akty Petra Velikogo. T. I. Akty o vysshikh gosudarstvennykh ustanovleniyakh. L., 1940. 926 s. [Review of «Legislative acts of Peter the Great. Vol. I» by N.A. Voskresensky], Sovetskoe gosudarstvo i pravo, no. 11, pp. 121-129. (in Russ.)

9. Tikhonov, V.V., 2016. Istoricheskie kampanii «pozdnego stalinizma» i sovetskaya istoricheskaya nauka: seredina 1940-kh - 1953 g. [Historical campaigns of «late Stalinism» and Soviet discipline of history, mid-1940s-1953)]. Sankt-Peterburg: Nestor-Istoriya. (in Russ.)

10. Yurganov, A.L., 2011. Russkoe natsional'noe gosudarstvo: Zhiznennyi mir istorikov epokhi stalinizma [Russian national state: the life-world of historians during Stalinist era]. Moskva: Izd-vo RGGU. (in Russ.)

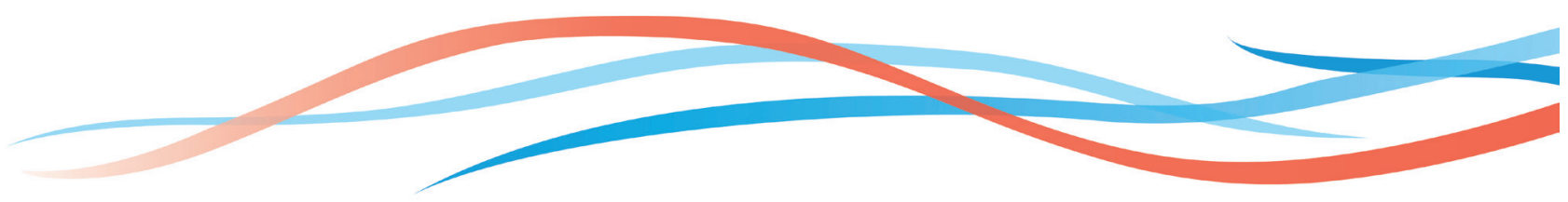

